\title{
Early transition from insulin to sulfonylureas in neonatal diabetes and follow-up: experience from China
}

\begin{abstract}
Background: Sulfonylurea therapy can improve glycemic control and ameliorate neurodevelopmental outcomes in patients suffering from neonatal diabetes mellitus (NDM) with $K C N J 11$ or $A B C C 8$ mutations. As genetic testing results are often delayed, it remains controversial whether sulfonylurea treatment should be attempted immediately at diagnosis or doctors should await genetic confirmation. Objective: This study aimed to investigate the effectiveness and safety of sulfonylurea therapy in Chinese NDM patients during infancy before genetic testing results were available. Methods: The medical records of NDM patients with their follow-up details were reviewed and molecular genetic analysis was performed. Sulfonylurea transfer regimens were applied in patients diagnosed after May 2010, and glycemic status and side effects were evaluated in each patient. Results: There were 23 NDM patients from 22 unrelated families, 10 had KCNJ11 mutations, 3 harbored $A B C C 8$ mutations, 1 had INS mutations, 4 had chromosome 6q24 abnormalities, 1 had a deletion at chromosome $1 \mathrm{p} 36.23 \mathrm{p} 36.12$, and 4 had no genetic abnormality identified. Sixteen NDM infants were treated with glyburide at an average age of 49 days (range 14-120 days) before genetic confirmation. A total of 11 of 16 (69\%) were able to successfully switch to glyburide with a more stable glucose profile. The responsive glyburide dose was $0.51 \pm$ $0.16 \mathrm{mg} / \mathrm{kg} / \mathrm{d}(0.3-0.8 \mathrm{mg} / \mathrm{kg} / \mathrm{d})$, while the maintenance dose was $0.30 \pm 0.07 \mathrm{mg} / \mathrm{kg} / \mathrm{d}(0.2-$ $0.4 \mathrm{mg} / \mathrm{kg} / \mathrm{d}$ ). No serious adverse events were reported. Conclusions: Molecular genetic diagnosis is recommended in all patients with NDM. However, if genetic testing results are delayed, sulfonylurea therapy should be considered before such results are received, even in infants with newly diagnosed NDM.
\end{abstract}

Keyword: Gene; Neonatal diabetes mellitus; Sulfonylurea; Therapy 